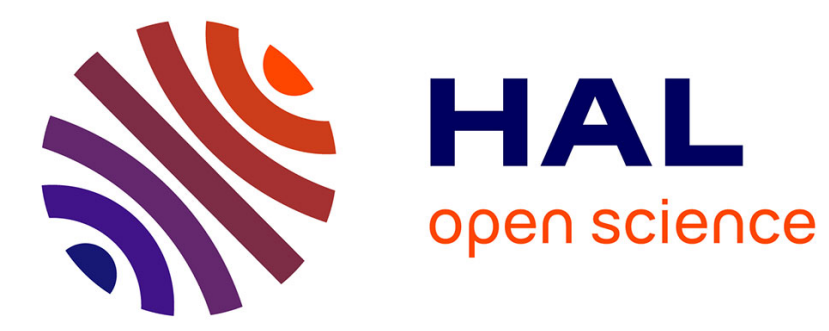

\title{
Beyond the Income Effect of International Trade on Ethnic Wars in Africa
}

\author{
Fabien Candau, T Gbandi, G Guepie
}

\section{To cite this version:}

Fabien Candau, T Gbandi, G Guepie. Beyond the Income Effect of International Trade on Ethnic Wars in Africa. 2021. hal-03265017v1

\section{HAL Id: hal-03265017 https://hal.science/hal-03265017v1}

Preprint submitted on 18 Jun 2021 (v1), last revised 12 Oct 2021 (v2)

HAL is a multi-disciplinary open access archive for the deposit and dissemination of scientific research documents, whether they are published or not. The documents may come from teaching and research institutions in France or abroad, or from public or private research centers.
L'archive ouverte pluridisciplinaire HAL, est destinée au dépôt et à la diffusion de documents scientifiques de niveau recherche, publiés ou non, émanant des établissements d'enseignement et de recherche français ou étrangers, des laboratoires publics ou privés. 


\title{
Beyond the Income Effect of International Trade on Ethnic Wars in Africa
}

\author{
F. Candau, ${ }^{*}$ T. Gbandi, ${ }^{\dagger}$ G. Guepie, ${ }^{\ddagger}$ \\ Forthcoming at The Economics of Transition
}

\begin{abstract}
We use detailed information on the location of agricultural and mining production to approximate international trade for different ethnic groups in order to study its impact on ethnic conflicts in Africa between 1993 and 2010. The goal is to go beyond the income effects of trade to study the residual effects of globalization on conflicts. We find that once we control for income but also for a wide variety of different factors in conflicts (using political variables and fixed effects), the international trade by ethnic groups has a pacific impact on conflicts. While this peaceful impact of trade is mainly found in the trade in agricultural products, it does not have a significant impact in the international trade in mining products. Finally, we propose an original two-step analysis showing that exports significantly reduce conflicts by affecting time-varying national characteristics. We interpret this result as an indication that globalization in Africa has participated in the formation of new national identities with peaceful effects between ethnic groups.

Key words: Ethnic Wars, Regional Trade, Globalization, National Identity, Africa.
\end{abstract}

\section{Introduction}

The purpose of this paper is to deepen our understanding of the impact of international trade on ethnic conflicts in Africa. Economists have analyzed in depth the effects of international trade on real incomes, which in turn have an impact on conflicts. But international trade can have a variety of other effects unrelated to prices and incomes. Our objective is specifically to study these non-monetary effects of international trade on conflicts. Imports, by affecting

*Universite de Pau et des Pays de l'Adour, E2S UPPA, CNRS, TREE, Pau, France.

†Universite de Pau et des Pays de l'Adour, E2S UPPA, CNRS, TREE, Pau, France.

$\ddagger$ United Nations Economic Commission for Africa, Addis Ababa, Ethiopia

§We are particularly grateful to Mathieu Couttenier, Carl Gaigné, Emmanuelle Lavallée, Julie Lochard, Marion Mercier for their insightful comments, stimulating discussions and encouragements on the different versions of this article. We are also very grateful to the editor, Alexandra Roulet, and to a reviewer for their careful reading and ideas for improving this research. 
consumption, threaten culture and local production. ${ }^{1}$ Exports influence institutions ${ }^{2}$ as well as the natural environment where goods are cultivated, extracted or manufactured. International trade is the final stage of successive interactions in different markets that are places of socialization. The whole process from production to export, or from border crossing to final consumption, can fuel tensions or, conversely, can pacify relations between the different ethnic groups of a country.

The impact of international trade that is channeled through non-monetary mechanisms is varied, ambiguous and defies simple categorization. For example, by promoting exchange, trade plays a role in building trust between communities ${ }^{3}$ but this peaceful effect can be reversed if the trading situation is seen as unfair. In a system of ethnic favoritism, unequal opportunities and lack of social mobility generate ethnic grievances (Gurr, 1970; Horowitz, 1985). Resentment against an ethnic hierarchical system may increase throughout the export process for every administrative formality that requires interaction with bureaucrats belonging to the dominant ethnic group (e.g. to obtain licenses and permits for production and export). ${ }^{4}$ International trade may also involve various types of forced exchanges between ethnic groups, thus generating an additional grievance mechanism. In all cases of forced exchanges where "the disadvantaged agent would no longer accept the trade if his disadvantage was removed" 5 , international trade can be detrimental regardless of the income generated. ${ }^{6}$ Forced trade can be a Pareto improvement bringing pecuniary benefits to all parties, but its unethical nature remains because the benefit to the exploited ethnic group is conditioned on its disadvantage.

International trade may be a threat to indigenous culture (Maystre, Olivier, Thoenig and Verdier, 2014), ${ }^{7}$ but the process of cultural homogenization can also help to relativize differences between ethnic groups. ${ }^{8}$ Globalization can also lead to cultural hybridization (Rauch and Trindade, 2009) where promoting a new national identity may have a peaceful effect. No great culture has risen in isolation according to Caplan and Cowen (2004), and globalization is a process that by enhancing the range of individual choices, yields forms of

\footnotetext{
${ }^{1}$ See Bisin and Verdier (2014) for a survey concerning the link between culture and trade.

${ }^{2}$ The classical example is the consequences of natural resource exportation on institutions and growth. See Ross (2015) for a survey on the resource curse.

${ }^{3}$ See Rohner et al. (2013) who present a dynamic relationship between trust and conflict that operates through trade.

${ }^{4}$ Another example of resentment is in the theft of products for export, where the loss of income is magnified by resentment against unfair access to the police or judicial system.

${ }^{5}$ Fleurbaey (2015).

${ }^{6}$ Forced trade occurs when the source of trade is related to the economic position of the agents (e.g. inequality). Sexual tourism is an emblematic example of forced trade but one can think of many other exchanges that can be classified in this category.

${ }^{7}$ The most emblematic example of this defense of indigenous culture was perhaps not in Africa but in Mexico where the Zapatistas group took up arms and occupied territory on January 1, 1994, the day the North American Free Trade Agreement (NAFTA) came into effect, with the clear aim of defending the culture of indigenous Mexican Indians.

${ }^{8}$ Many regional trade agreements in Africa, including the recent African Continental Free Trade Agreement, have the objective of fostering peace through economic integration and growth, but also through cultural exchanges. This can be seen in many political discourses about the necessity to reunify ethnicities that have been separated by arbitrary borders. For example, on the website of the East African Community, where different zones of conflict have exploded in the past, one can read that "the mission of the Community is to widen and deepen economic, political, social and cultural integration".
} 
expression within cultures that may provide new opportunities of exchanges between groups. ${ }^{9}$

Finally, a negative side effect of international trade is that it can destroy the natural environment of different groups (via deforestation or by increasing local pollution ${ }^{10}$ ) which may be a source of conflict.

The research question of the current paper is not to analyze these different effects, which are certainly too numerous to be studied in a single paper, but to determine the net effect of all of them. Such a question is important because by not taking these effects into account, the impact of international trade may be underestimated and/or misattributed solely to its income effects, with important policy consequences. For instance, place-based policies or redistribution from the winners to the losers of international trade may be ineffective in easing conflicts.

We focus on ethnic wars because these conflicts have been numerous in Africa. Since 1960, more than half of Africa's civil conflicts that have occurred in 42 out of a total of 54 African countries have been ethnic conflicts. ${ }^{11}$ Moreover, studying these issues at the ethnic level provides a better understanding of the mechanisms at play. To accurately analyze the impact of international trade on conflicts, it is crucial to determine which groups are involved and what are the gains or losses at the local level. This information matters to control for the revenues generated and then to identify the residual effects of international trade. The geographical basis of ethnic groups is an advantage to lead this empirical strategy. Data concerning international trade and income are not collected at the ethnic level, but it is possible to approximate them by focusing on particular products where the location of production can be identified at the ethnic level. Using the geographical distribution of 175 crops on a $10 \mathrm{~km}$ by $10 \mathrm{~km}$ cell grid (Monfreda et al., 2008) and the spatial distribution of mineral resources in Africa, we build a proxy of the international trade by ethnic groups concerning these goods. These products are informative for analyzing whether the nonmonetary effects of international trade are general or depend on the goods traded. Finally to approximate income at the ethnic level, we use nightlight pictures provided by satellites (Henderson et al., 2012). Since these data are not completely reliable in rural areas, we also used climate variables that explain a significant portion of the conflicts, either directly or indirectly (via income change) in these regions.

Using this data for a panel of 37 African countries over the period 1993 to 2010, we find that international trade reduces the probability of ethnic warfare. This result, obtained by controlling for income, climate change and institutions, is an indication in favor of our thesis that trade has effects beyond the one traditionally analyzed. However, the resulting coefficient may be biased for various reasons due to omitted variables or measurement errors (even if we use a rich set of fixed effects). We therefore propose a different identification strategy by adopting a two-step approach. The first step aims to assess the importance of income variation at the ethnic level relative to other variations occurring at the national level as a source of conflict. The source of identification is based on the fact that some ethnic groups have been divided by arbitrary borders while other ethnic groups have not.

\footnotetext{
${ }^{9}$ Cowen (2007) develops the thesis that globalization, by increasing the menu of choices, leads to cultural creation rather than to cultural destruction. The impact on conflicts of this facet of globalization, has however to our knowledge never been studied.

${ }^{10}$ See Candau and Dienesch (2017) for an analysis of the pollution haven effects in developing countries.

${ }^{11}$ Source: Ethnic Power Relations database
} 
We can therefore isolate the "national component" of ethnic conflicts to study in a second step how international trade has modified it. ${ }^{12}$ Formally, we regress the likelihood of civil conflicts on national time-varying characteristics (captured with country-year fixed effects), income at the ethnic level, ethnic and time-fixed effects. The second stage uses the country time varying effects estimated in the first stage and regresses the predicted values on the total exports of countries (and a set of time dummies and controls). We find that exports significantly reduce conflicts by affecting these time-varying national characteristics. Our interpretation is that international trade has peaceful effects inside countries by promoting new national identities in Africa.

Regarding the literature and the link between international trade and conflicts, Martin et al. (2008b) use the ratio of trade flows to income as a measure of international trade and find that the higher the ratio the less the probability of high-intensity war conflicts. In comparison we distinguish these two variables to decompose the direct effects of trade and its effects on income and find that these two components have peaceful effects. Bazzi and Blattman (2014) study the impact of plausibly exogenous global shocks on food prices to study how these shocks, by having a catastrophic impact on incomes, influence conflicts. They find that rising prices have no effect on the emergence of new conflicts but reduce their duration. However, this analysis does not exploit the variations of international trade at the subnational level. Regarding this last point, our study is more similar to that of Berman and Couttenier (2015) who analyze external shocks such as the impact of changes in global demand for agricultural products produced by regions within countries. They find that an increase in global demand significantly decreases the probability of conflict incidence. McGuirk and Burke (2020) also use food price shocks, and find that higher food prices increase conflicts over surplus appropriation but reduce it over control of territory. Typically in such a context, our contribution is to take into account the ethnic component of conflicts that matters in each of these appropriation and control mechanisms. Finally, there are many articles that analyze the importance of the nature of the exported goods to explain conflicts. In Colombia, Dube and Vargas (2013) find that the sharp decline in international coffee prices in the 1990s led to more violence in coffee-producing municipalities than in other municipalities. An inverse relationship was found for mineral commodities: a 10\% increase in the price of oil led to a $2 \%$ increase in the number of conflict events in Nigeria according to Cali (2015). Similar results were found for the Democratic Republic of the Congo (Maystadt et al. 2014), and for sub-Saharan Africa (Berman and Couttenier, 2015). What are study show here is that international agricultural trade promotes peace while the international trade in mining products does not have a significant effect. These results are obtained with numerous controls such as political variables, climate change and fixed effects all defined at the ethnic group level: our results are thus much more conditional than those obtained in the literature (such as those just quoted for Colombia, Nigeria and the Congo). For instance, regarding agricultural trade, ethnic fixed effects enables to control for the heterogeneity of ethnic groups such as the unequal access to fertile land between ethnicities. ${ }^{13}$ This means

\footnotetext{
${ }^{12}$ Indeed, in many African countries a significant portion of the population belongs to ethnic groups that are partitioned among different states. See Michalopoulos and Papaioannou (2016) for a deep analysis of the long-run consequences of ethnic partitioning in Africa.

${ }^{13}$ see Berman, Couttenier and Soubeyran (2021) who typically show that an unfair distribution of land is a fertile ground for conflicts
} 
that the peaceful impact of international trade found here is possible once problems related to inequality between ethnicities are addressed.

We are not aware of any work using proxy data on income, climate, and trade at the ethnic group level, or of developing a similar two-stage approach to studying civil wars. This two-stage regression, presented here, was first proposed in labor economics (Abowd et al., 1999) and is now a standard method used in geographical economics to analyze agglomeration economies (Combes, Duranton and Gobillon, 2008), but has never been used in the analysis of conflicts.

Finally, there are many articles in political science that analyze the role of non-economic factors such as grievances and social sanctions in explaining why some individuals choose to participate in armed conflict, but these studies have not analyzed the role of international trade as we do here. ${ }^{14}$

The rest of the paper is structured as follow. Section 2 and 3 present respectively the empirical strategy and the results concerning the effects of trade integration on conflicts. Section 4 discusses our two-step approach and presents the results concerning the impact of trade on the time-varying characteristics of countries that affects wars.

\section{Empirical Strategy}

\subsection{Baseline Regression}

In the literature, three mechanisms are often put forward to explain how international trade affects conflicts. The first one is the opportunity cost effect, when trade shocks reduce income, the cost of participating in violent actions follows suit. ${ }^{15}$ The second is the resource effect, also called the "state capacity" mechanism. Trade raises tax revenues and can then improve the government's ability to buy peace by financing public goods and redistributing funds to rebels. ${ }^{16}$ The third one, is the rapacity effect, and a resource that has a high value arouses envy and the risk of expropriation that can degenerate into conflict. ${ }^{17}$

All these mechanisms have a common ground, as trade affects conflicts through its impact on real incomes which is presented in the following Directed Acyclic Graphs (DAG) in Figure (2.1). But, as we argue in the introduction, trade can also have a myriad of effects through its impact on culture, on the socialization of the population, and on the alteration of the natural environment in which ethnic groups live. Finally, many factors influence income and conflicts simultaneously, making the study of the effects of trade on conflicts quite challenging.

\footnotetext{
${ }^{14}$ See Humphreys and Weinstein (2008) for a brief survey and a call to consider all the determinants in the conflicts participation decision-making since recruitment strategies often exploit both economic and non-economic arguments.

${ }^{15}$ Montesquieu (1758), Mayer, Martin and Thoenig (2008.a).

${ }^{16}$ See Angrist and Kugler (2008) who analyze how the increase in the price of coca in Columbia, in part driven by the American demand, has raised revenues for the guerrilla.

${ }^{17}$ The rapacity effect is often analyzed by studying trade in mineral products. According to Cali (2015) a $10 \%$ increase in the price of oil, raises the risk of conflict by 2.2 percent on average across countries.
} 
Figure 1: Directed Acyclic Graphs of Trade and Conflicts

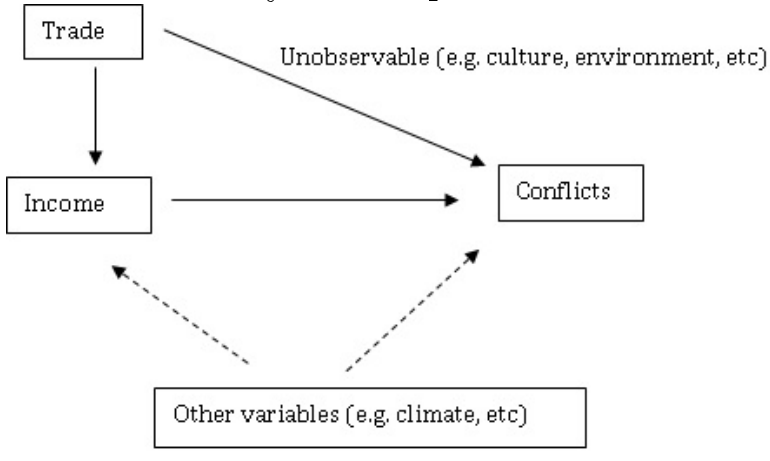

To present this discussion in equations, let's consider that the international trade of an ethnicity $r$ in country $i$ at time $r$, denoted $\phi_{r i t}$, influences incomes, $Y_{r i t}$, which affect conflicts. But as already mentioned, the likelihood to enter in conflicts with/for this particular ethnic group $r, \operatorname{Pr}\left(w a r_{r i t}\right)$, also depends on the effect of trade related mechanisms that are difficult to measure such as socialization, culture, lasting grievances due to environmental destructions or to unfair conditions. In that case, the simple solution to determine the direct effect of trade on conflicts is to control for incomes and for all unobservable effects via the following specification:

$$
\operatorname{Pr}\left(w_{a r} r_{r i t}\right)=\gamma_{0}+\gamma_{1} \phi_{r i t}+\gamma_{2} Y_{r i t}+\gamma_{3} E_{r i t}+Z_{i t}+f_{r}+f_{t}+\epsilon_{r i t}
$$

where $E_{r i t}$ is a set of ethnic group-level variables introduced as controls (e.g., a dummy variable when an ethnic group is systematically excluded from the central government) and climate variables at the level of each ethnic group (temperature and rainfall). Climate change is indeed well known to affect both incomes and conflicts. For example, rainfall was used as an income instrument to explain conflicts (e.g. Miguel et al. 2004) until the finding that this variable also has a direct effect on conflicts (see Hsiang et al. 2013).

The country-year controls $Z_{i t}$ is a vector of country-level variables taking into account the economic and political context (such as the quality of institutions and economic characteristics).

The term $f_{r}$ represents time-invariant characteristics of ethnic groups and controls for variables that simultaneously affect incomes and conflicts at the ethnic-country level. For instance, a constant discrimination against $r$ over a long period of time is taken into account by $f_{r}$. But these fixed effects also capture factors related to trade such as the long-lasting effect of grievance of forced trade emphasized in the introduction. Finally $f_{t}$ allows to get rid of time specific shocks.

Using this rich set of fixed effects enables to treat the classical problem of omitted variables. But it has an additional advantage regarding Figure (2.1). Indeed, controlling for income but not for all the other variables that affect conflicts and incomes, create a new pattern of bias, since incomes are considered in this DAG as a collider (or in the word of Angrist and Pischke (2009) as a "bad control"). Then our specification allows to control for incomes and for all the unobservable characteristics to get an unbiased estimate of $\gamma_{1}$.

Finally, the analysis of the causal link from trade to conflicts, that controls for incomes, faces a problem of reverse causality: incomes, growth and international trade are influenced 
by conflicts. Thus, instead of relying on contemporaneous variables at the right-hand side of Equation (1), we use their lags by one year to alleviate endogeneity issues. Obviously the endogeneity concern certainly persists, but there are no credible instruments that explain conflicts only through international trade, at the ethnic level, without affecting income. Similarly, we have not found any instrument that respects the exclusion restriction concerning incomes.

Considering the binary nature of our dependent variable, the logit or probit model appears the right choice. Nevertheless, we rely on a Linear probability model (LPM) strategy, because there is a drastic loss in the data when we introduced fixed-effects in the logit model estimates. $^{18}$

\subsection{How to measure trade, income and other determinants of con- flicts?}

This study concerns 37 African countries over the period 1993 to $2010{ }^{19}$

The probability of war, $\operatorname{Pr}\left(w a r_{r i t}\right)$, is approximated by the onset of a new ethnic civil war and comes from the Ethnic Power Relation (EPR) database compiled by Wimmer et al. (2009). It is a binary variable taking one when an ethnic group is engaged in a new ethnic war in a given year and zero otherwise. These data make it possible to distinguish pure civil war from ethnic war ${ }^{20}$ based on PRIO/UCDP conflicts database.

Estimating the equation (1) is challenging because there is no data on international trade and income of ethnic groups. Yet this information is crucial to understanding the causes of conflict. For example, the various studies that have analyzed the impact of trade on conflict using country-level data (e.g., Martin et al., 2008b), assume that country specialization is spatially homogeneous within a country.

Similarly, by taking the GDP of countries as a proxy for income, researchers cannot control for the distributional effects of trade. Thus, they cannot distinguish between a situation in which trade promotes economic growth for all, and a situation in which the gains of winners exceed the losses of losers, which is problematic because these two situations can have very different effects on conflict.

We measure the income of an ethnic homeland $r$ in country $i$ at time $t, Y_{\text {rit }}$, by exploiting night light pictures provided by satellites. There is now a large literature that uses these data as a proxy for income at the national and subnational level (Henderson et al., 2012; Gibson

\footnotetext{
${ }^{18}$ The fixed-effects predict perfectly the dependent variable of both ethnic groups that never experience a conflict and ethnic groups that hosted conflicts during the entire period of the study.

${ }^{19}$ List of countries: Algeria, Angola, Benin, Botswana, Burundi, Cameroon, Central African Republic, Chad, Egypt, Eritrea, Ethiopia, Gabon, Gambia, Ghana, Guinea, Guinea-Bissau, Kenya, Liberia, Madagascar, Malawi, Mali, Mauritania, Morocco, Mozambique, Namibia, Niger, Nigeria, Rwanda, Senegal, Sierra Leone, South Africa, Sudan, Tanzania, Togo, Uganda, Zambia, Zimbabwe.

${ }^{20}$ More precisely, Wimmer, Cederman and Min (2009) define ethnic wars as follows: "we distinguish between ethnic and non-ethnic conflicts using the aims of the armed organization and their recruitment and alliance structures (...) We identify as "ethnic" the aims of achieving ethnonational self-determination, a more favorable ethnic balance-of-power in government, ethnoregional autonomy, the end of ethnic and racial discrimination, language and other cultural rights, and so forth. In ethnic wars, armed organizations also recruit fighters predominantly among their leaders' ethnic group and forge alliances on the basis of ethnic similarity"
} 
et al., 2021). While there is debate about the accuracy of these data (see Gibson et al., 2021), they have the advantage of being independent of national statistical agencies that often do not measure activities during conflict (or may manipulate the data) and available at the regional level. According to Michalopoulos and Papaioannou (2018): "it is clear that luminosity can be a powerful proxy of economic activity for regional analyses in war-prone countries [...] these are precisely the regions where understanding the causes of underdevelopment is likely to be of greater value". Furthermore, in many African countries, these data were matched with surveys (in particular with Demographic and Health Surveys) and the authors verified the significant and high regional correlation between brightness and survey-based measures of household well-being (Michalopoulos and Papaioannou, 2013, 2018; Weidmann and Schutte, 2017, Bruederle and Hodler, 2017).

In order to get the night light intensity at ethnic group level, we use ESRI African countries shapefile that we merge with Murdock (1959) ethnic group's boundaries shapefile. Night lights raster come from the National Oceanic and Atmospheric Administration (NOAA) and are available from 1992 to 2013. A raster contain pixels of approximately one kilometer square. Every pixel is associated to a number that goes from 0 to 63 indicating the brightness of the light. These rasters are matched with the shapefile of ethnic group's boundaries and the mean night lights density is computed within each ethnic group-country boundaries for every year using geomatic tools. Since satellite pictures do not distinguish gaze flaring activities from real lights, we exclude the corresponding spatial areas. The drawback of night light pictures are well known, the most significant concerning our study lies in the inability of these pictures to detect low density areas (see Nordhaus and Chen, 2015; Gibson et al. 2021). However, we expect to control for the source of conflicts in these areas by using climate variables. In support to this strategy McGuirk and Nunn (2020) analyze why "herder-farmer" conflicts have erupted in recent years in Africa and find that the source of these tensions are linked to climate change. They show that agropastoral conflicts are caused by the displacement of pastoral groups due to low rainfall in their homelands. Therefore, precipitation and temperature data can compensate for the lack of nightlight data to control income changes and other (more direct) factors of ethnic wars in rural areas. Considering these direct factors, Sarsons (2015) shows, for example, that rainfall explains large infrastructure investments, such as dams, that have direct effects on conflict.

We construct the climate variable following the same geomatic techniques. We compute a temperature and precipitation indicator at the ethnic level by relying on WorldClim raster $^{21}$. WorldClim provides 2.5 minutes $(\sim 21 \mathrm{~km} 2)$ spatial resolution of monthly average maximum temperature $\left({ }^{\circ} \mathrm{C}\right)$, monthly average minimum temperature $\left({ }^{\circ} \mathrm{C}\right)$ and monthly total precipitation (mm) for the Earth's land surface for the years 1960 to 2018. Thus, we firstly compute the monthly average minimum temperature, the monthly average maximum temperature and the monthly average precipitations within each country-ethnic group homeland from 1992 to 2010. With these data we compute the yearly average minimum and maximum temperature with the yearly total precipitations recorded for all the countryethnic group's homeland. As for the yearly average temperature, it is finally computed as (maximumtemperature + minimumtemperature) $/ 2$.

Apart from the ethnic level climates variables, the vector of ethnic-country-year controls

\footnotetext{
${ }^{21}$ https://www.worldclim.org/data/monthlywth.html\#
} 
$E_{\text {rit }}$ in Equation (1) comprises also a dummy taking 1 when the ethnic group is excluded from the central government and 0 otherwise. It comes from the Ethnic Power Relations database. ${ }^{22}$ The vector of country level variables $Z_{i t}$, that is to say countries growth (approximated with GDP growth) and countries population size come from World development indicators (WDI ) while institutions quality (approximated with Polity2 score of democracy) is extracted from PolicyIV project database.

To compute the international trade at the ethnic level, we use a weighting scheme based on trade in agricultural goods and natural resources. The trade variables come from BACI, a database developed by CEPII, and are combined with other sources, described below. Formally the sum of exports in the agricultural sector, denoted $a$, and the mining sector, $m$, are taken into account as follows:

$$
\phi_{\text {rit }}=\sum_{a=1}^{45}\left(p_{\text {ria }} * X_{i t a}\right)+\sum_{m=1}^{48}\left(p_{\text {rim }} * X_{i t m}\right)
$$

$X_{i t k}$ represents country $i$ exportation at year $t$ for a good in sector $k=a, m$; $a$ designs the agricultural goods and $m$ the mining goods. The weight $p_{\text {ria }}$ is the ratio of the ethnic group production of a good in the agriculture sector on it national output, such as $p_{\text {ria }}=\frac{E_{\text {ria }}}{E_{i a}}$ where $E_{\text {ria }}$ is the sum of the mean production of crop $a$ by the ethnic group $r$ (in country $i$ ) over the period 1997-2003, and $E_{i a}$ is the sum of the mean production of crop $a$ in country $i$ over the same period.

As for agricultural products, after identifying natural resources location toward Africa, we build ethnic weight of every resource product as $p_{\text {rim }}=\frac{S_{\text {rim }}}{\sum_{g} S_{\text {gim }}}$, where $S_{\text {rim }}$ is the area (surface) of the ethnic group where the mineral product $m$ is localized and $S_{\text {gim }}$ represents the surface of each of the ethnic groups $g$ in the country $i$ that exploits this resources $m$.

We focus on the export of agricultural goods and mineral products because these two sectors account for a large share of exports in Africa. The results are presented using this general definition, but also by analyzing agricultural trade separately (in that case $\left.\phi_{\text {rit }}=\sum_{a=1}^{45}\left(p_{\text {ria }} * X_{\text {ita }}\right)\right)$ and international trade in mineral goods by ethnic groups $\left(\phi_{\text {rit }}=\right.$ $\left.\sum_{m=1}^{48}\left(p_{\text {rim }} * X_{\text {itm }}\right)\right)$.

Since the weighting system is based on the production of agricultural and mineral goods at the ethnic level, we need to geo-locate these productions and to match them to the geographic boundaries of ethnic groups.

Concerning the agricultural sector, we rely on geographical global data set (raster) of croplands on a 5 minute by 5 minute $(\sim 10 \mathrm{~km}$ by $10 \mathrm{~km})$ latitude/longitude grid extracted from EarthStat ${ }^{23}$ that provides information on land use concerning "Harvested Area and Yield" (see Monfreda et al., 2008). This database contains raster on $175^{24}$ agricultural products with four raters per crop comprising pixels of 10 times 10 square kilometers over the period 1997-2003. As a result, we have information on (i) the average proportion harvested for a given agricultural product; (ii) the average number of hectares harvested per pixel; (iii) the total production of the crops in tons over each pixel; and (iv) the quality of the data

\footnotetext{
${ }^{22}$ https://icr.ethz.ch/data/epr/

23 http://www.earthstat.org/

${ }^{24}$ It should be noticed that upstream work has been done to match the products name from EarthStat with those from Baci. At the end of this exercise, 47 raster out of the 175 in EarthStat were retained.
} 
according to their sources. We mainly use raster about the production of crops (in tons) in order to account that some agricultural products are harvested more than once a year. Figure (2) shows the coverage of cotton and cassava in Africa. The more a pixel is bright, the higher the production within the area covered.

Figure 2: Crops production imagery: cotton and cassava
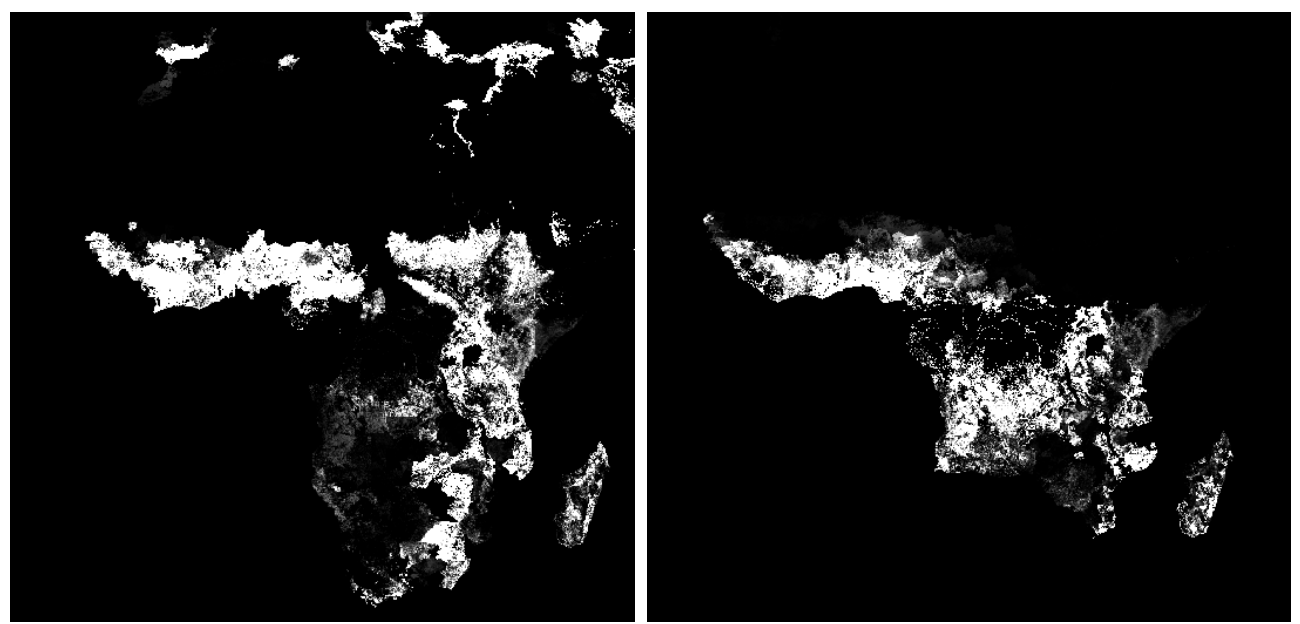

Source: Author's map based on the data of Monfreda et al. (2008).

These data are then merged with the spatial coverage of ethnic group reported by Murdock (1959) and digitized by Nathan Nunn. ${ }^{25}$ Finally we calculate the production within each ethnic groups area for the different crops identified (48 different crops), which gives $E_{r i a}$. Once divided by the national production $E_{i a}$, we get our weight of the national export $p_{\text {ria }}$.

Concerning mining resources, we use the U.S. Geological Survey ${ }^{26}$ enabling to locate mining resources toward Africa. This survey provides data on the spatial location of a large panel of mineral resources all around the world (Mineral Resources Data System / MRDS) with the name of the deposit, the deposit description, the geological features, the data source and references. ${ }^{27}$ Then, we merge the Murdock (1959) map of ethnographic regions shape file, with countries boundaries ${ }^{28}$ and finally with the resources locations shapefile in order to identify in which ethnic group and country the natural resources are located. Figure (2.2) illustrates a part of this computation by presenting the different mineral resources location at the ethnic level.

\footnotetext{
${ }^{25}$ https://worldmap.harvard.edu/data/geonode:murdock_ea_2010_3

${ }^{26}$ https://mrdata.usgs.gov/mrds/

${ }^{27}$ https://mrdata.usgs.gov/mrds/package.php

${ }^{28}$ ESRI Shape file format: http://www.maplibrary.org/library/stacks/Africa/index.htm
} 
Figure 3: Mineral resources location in Africa at the ethnic/country level

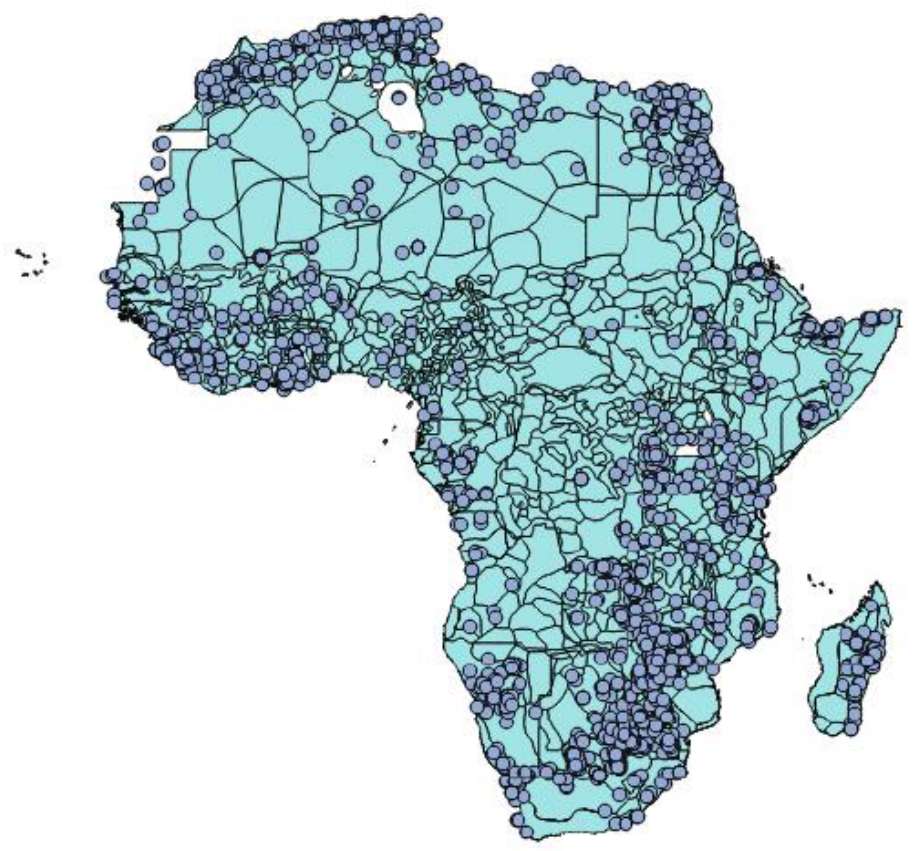

Source: Author's map based on Murdock (1959) and the Mineral Resources Data System.

\section{Results}

Table (1) presents the results of the estimation of Equation (1). In Column 1, conflicts are simply regressed on international trade and we get a negative sign. This correlation is however not conditioned by all other possible determinants of trade and conflicts. In Column 2, the classical problem of introducing a collider, namely income in this relationship, is illustrated since as usually in this case, the variable of interest is no longer significant (see Cunningham, 2021, e.g. Table 9, p. 110). To resolve this issue we need to control for all other determinants of income and conflicts which is done in Column 3 by using time and ethnic group fixed effects and in Column 4 by adding time-varying variables (Polity, GDP growth, climate variables). We find that the indicator of international trade at the ethnic level significantly reduces the likelihood of conflicts. Column 5 even goes beyond the specification proposed in Equation (1) by introducing country-year fixed effects. It is worthnoting that the R-squared in this column increases drastically compared to that from the first four columns and this justifies the importance of countries context in explaining ethnic conflicts. 
Table 1: International Trade effect on ethnic wars onset

\begin{tabular}{|c|c|c|c|c|c|}
\hline & (1) & (2) & (3) & $(4)$ & (5) \\
\hline & \multicolumn{5}{|c|}{ International trade } \\
\hline Trade $\left(\phi_{\text {rit }}\right)$ & $\begin{array}{c}-0.0006^{* *} \\
(0.0005)\end{array}$ & $\begin{array}{l}-0.0002 \\
(0.0005)\end{array}$ & $\begin{array}{c}-0.0013^{* *} \\
(0.0005)\end{array}$ & $\begin{array}{c}-0.0012^{* * *} \\
(0.0005)\end{array}$ & $\begin{array}{c}-0.0018^{* *} \\
(0.0008)\end{array}$ \\
\hline Income $\left(Y_{\text {rit }}\right)$ & & $\begin{array}{c}-0.0021^{* * *} \\
(0.0007)\end{array}$ & $\begin{array}{c}-0.0042^{* *} \\
(0.0021)\end{array}$ & $\begin{array}{c}-0.0041^{* *} \\
(0.0021)\end{array}$ & $\begin{array}{l}-0.0038 \\
(0.0024)\end{array}$ \\
\hline Excluded ethnic groups & & & $\begin{array}{c}0.0079^{* *} \\
(0.0032)\end{array}$ & $\begin{array}{c}0.010^{* * *} \\
(0.0037)\end{array}$ & $\begin{array}{c}0.0258^{* * *} \\
(0.0089)\end{array}$ \\
\hline Population size & & & & $\begin{array}{c}0.0014 \\
(0.0345)\end{array}$ & \\
\hline Polity2 & & & & $\begin{array}{c}0.0004 \\
(0.0003)\end{array}$ & \\
\hline Polity2 square & & & & $\begin{array}{c}.00002 \\
(0.00003)\end{array}$ & \\
\hline GDP growth & & & & $\begin{array}{c}0.0002^{* * *} \\
(0.0001)\end{array}$ & \\
\hline Temperature & & & & $\begin{array}{c}-0.0003 \\
(0.0004)\end{array}$ & $\begin{array}{c}0.0003 \\
(0.0008)\end{array}$ \\
\hline Precipitation & & & & $\begin{array}{c}0.0056^{* * *} \\
(0.0019)\end{array}$ & $\begin{array}{c}0.0142^{*} \\
(0.0072)\end{array}$ \\
\hline Constant & $\begin{array}{c}-0.0069^{* * *} \\
(0.0023)\end{array}$ & $\begin{array}{l}-0.0017 \\
(0.0023)\end{array}$ & $\begin{array}{l}-0.0093 \\
(0.0080)\end{array}$ & $\begin{array}{c}-0.1465^{* * *} \\
(0.0512)\end{array}$ & $\begin{array}{c}-0.3535^{* *} \\
(0.1788)\end{array}$ \\
\hline Observations & 5570 & 5570 & 5570 & 5570 & 5570 \\
\hline R-squared & 0.001 & 0.007 & 0.018 & 0.019 & 0.222 \\
\hline Year FE & No & No & Yes & Yes & Yes \\
\hline Ethnic Group FE & No & No & Yes & Yes & Yes \\
\hline Country-year FE & No & No & No & No & Yes \\
\hline
\end{tabular}

Notes: The dependent variable is a binary variable taking 1 when an ethnic group is engaged in a new ethnic war in a given year. All explanatory variables are lagged by one year excepted climate variables. Ethnic group-country level clustered robust standard errors reported in parentheses. $* * *(* *)(*)$ denote significance at the 1,5 and 10 percent level respectively.

In Table (2) we lead the same analysis (reproducing the previous Column 4 and 5) but by separating agricultural goods and mineral products. Clearly the peaceful impact of trade is driven by agricultural products. The international trade in mineral products has no significant effects on conflicts. This result may have different origins. First, we have attributed mining operations to ethnic groups by considering a geographical criterion that may not be accurate (e.g. mines are exploited by ethnic groups other than the ones where the mines are located). Secondly it is possible that our results are valid, namely that trade flows have on average over the period considered no residual significant effect. This however does not invalidate the fact that sudden changes in the price of mineral goods can have strong effects on conflicts (but are captured by our time effects). 
Table 2: International Trade effect on ethnic wars onset

\begin{tabular}{|c|c|c|c|c|}
\hline & $(1)$ & $(2)$ & $(3)$ & $(4)$ \\
\hline \multirow{3}{*}{ Trade $\left(\phi_{\text {rit }}\right)$} & \multicolumn{2}{|c|}{ Agricultural goods } & \multicolumn{2}{|c|}{ Mineral goods } \\
\hline & $-0.0017^{* *}$ & $-0.0040^{* *}$ & -0.0001 & -0.0001 \\
\hline & $(0.0007)$ & $(0.0017)$ & $(0.0003)$ & $(0.0001)$ \\
\hline \multirow[t]{2}{*}{ Income $\left(Y_{\text {rit }}\right)$} & $-0.0043^{* *}$ & -0.0039 & -0.0003 & -0.0007 \\
\hline & $(0.0022)$ & $(0.0025)$ & $(0.0007)$ & $(0.0006)$ \\
\hline \multirow[t]{2}{*}{ Excluded ethnic groups } & $0.0101^{* * *}$ & $-0.0256^{* * *}$ & 0.0114 & 0.0079 \\
\hline & $(0.0037)$ & $(0.0089)$ & $(0.0071)$ & $(0.0067)$ \\
\hline \multirow[t]{2}{*}{ Population size } & -0.0016 & & -0.0481 & \\
\hline & $(0.0366)$ & & $(0.0948)$ & \\
\hline \multirow[t]{2}{*}{ Polity2 } & 0.0004 & & 0.0003 & \\
\hline & $(0.0003)$ & & $(0.0002)$ & \\
\hline \multirow[t]{2}{*}{ Polity2 square } & 0.00002 & & 0.0001 & \\
\hline & $(0.00003)$ & & $(0.0001)$ & \\
\hline \multirow[t]{2}{*}{ GDP growth } & $0.0002^{* * *}$ & & 0.0002 & \\
\hline & $(0.0001)$ & & $(0.0001)$ & \\
\hline \multirow[t]{2}{*}{ Temperature } & 0.0003 & 0.0003 & -0.0002 & -0.0002 \\
\hline & $(0.0004)$ & $(0.0008)$ & $(0.0004)$ & $(0.0002)$ \\
\hline \multirow[t]{2}{*}{ Precipitation } & $0.0058^{* * *}$ & $0.0148^{*}$ & -0.0016 & -0.0052 \\
\hline & $(0.0020)$ & $(0.0078)$ & $(0.0017)$ & $(0.0046)$ \\
\hline \multirow[t]{2}{*}{ Constant } & $-0.0059^{* * *}$ & 0.0061 & -0.0052 & -0.0023 \\
\hline & $(0.0081)$ & $(0.0123)$ & $(0.0048)$ & $(0.0022)$ \\
\hline Observations & 5399 & 5399 & 1421 & 1421 \\
\hline R-squared & 0.019 & 0.223 & 0.015 & 0.757 \\
\hline Year FE & Yes & Yes & Yes & Yes \\
\hline Ethnic Group FE & Yes & Yes & Yes & Yes \\
\hline Country-year FE & No & Yes & No & Yes \\
\hline
\end{tabular}

Notes: The dependent variable is a binary variable taking 1 when an ethnic group is engaged in a new ethnic war in a given year. All explanatory variables are lagged by one year excepted climate variables. Ethnic group-country level clustered robust standard errors reported in parentheses. $* * *(* *)(*)$ denote significance at the 1,5 and 10 percent level respectively.

\section{Inference from a two step strategy}

\subsection{Empirical strategy}

The previous analysis aims at using commonly and widely known strategy to identify the effect of trade on war. However, by merging aggregate data (country level variables) to micro observations (ethnic groups) we make a strong assumption of independent disturbances which may be not verified for data with grouped structure (Moulton, 1990). In that case, OLS standard errors can be biased downward leading the aggregated variables to be artificially significant. Furthermore single-stage estimation is problematic because we mislead country shocks affecting conflicts with idiosyncratic risk. For instance by controlling for each ethnicity 
by fixed effects we also control for variables that affects the whole country, we thus loss an information about the social cohesion between ethnies or about the national identity that transcend them. This is a difficulty in our context because our aim is precisely to analyze how international trade affect these elements. Moreover, if non-monetary effects of trade are captured by $f_{r}$ (because of low variations for instance), then $\operatorname{Cov}\left(\phi_{\text {rit }}, f_{r}\right) \neq 0$ and there is a problem of endogeneity bias which is certainly reinforced by the fact that income and trade are also correlated $\left(\operatorname{Cov}\left(\phi_{\text {rit }}, Y_{\text {rit }}\right) \neq 0\right)$.

Thus, on the basis that these country fixed-effect may deliver helpful information, we propose a two steps estimation approach to explore the extent to which the country features that influence ethnics wars are driven by trade. The first stage is an estimation of the probability of wars on income $\left(Y_{\text {rit }}\right)$, country-year effects $\left(f_{i} \times f_{t}\right)$, and ethnic group's fixed effects $\left(f_{r(i)}\right)$ such as:

$$
\operatorname{Pr}\left(\text { war }_{\text {rit }}\right)=\gamma_{1} Y_{\text {rit }}+f_{i} \times f_{t}+f_{r}+\epsilon_{\text {rit }}
$$

The estimated country-year fixed effects $\left(f_{i} \widehat{\times} f_{t}\right)$ from the specification above thus captures the change in national features that influences conflicts after controlling for observed $\left(Y_{\text {rit }}\right)^{29}$ and the set of ethnic characteristics $\left(f_{r}\right)$. These fixed effects are particularly interesting and valuable insofar as we have in our database, two kind of ethnic groups; the ones that belong exclusively to one country and those that are shared by at least two countries. The identification of differences in term of wars between countries comes from the ethnic groups that have been partitioned. Actually, we can argue that partitioned ethnic groups may share the same characteristics (that we control for with ethnic fixed effects $f_{r}$ ) but may follow different path of development and stability because of the influence of the country they now belong to. Then everything that varies for these partitioned ethnic groups may comes from the national context measured by the country-year fixed effects $\left(f_{i} \times f_{t}\right)$.

In the second step, we analyze how trade, now measured at the country $i$ and time $t$ level, explains change in national features $\left(f_{i} \widehat{\times} f_{t}\right)$ that make a country a home to conflicts:

$$
\widehat{f_{i} \times f_{t}}=\gamma_{1} \phi_{i t}+Z_{i t}+f_{t}+\epsilon_{i t}
$$

In other words, these equations allow to capture how trade, by driving changes in the national context $f_{i} \times f_{t}$, shapes the latter with regard to the occurrence of ethnic conflicts. The predicted $\left(f_{i} \times f_{t}\right)$ from the first-step is thus used as the dependent variable in the second-step regression. It is noteworthy that, since these changes are beyond the ethnic group's income effect, our second stage enables to assess the effect of trade on non-monetary variables at the national level.

This strategy has been previously used in labor economics (Abowd et al., 1999) and in urban economics (Combes et al., 2008, Puga and De la Roca, 2017). In the latter field, this technique is used to capture the urban agglomeration effect on wages. In the first step, wages (here conflicts) regress on individual time-varying characteristics (here ethnicity), and on city-year fixed effects (here countries). In the second step, the city-year fixed effects are regressed on an indicator of agglomeration (e.g. density). The net benefit of agglomeration

\footnotetext{
${ }^{29}$ Income can also be endogenously determined by conflicts. Here, we still present results with a lag of one year to reduce this problem; similar results with different lag are also obtained (not reported but available on request).
} 
is identified from the changes in wages that a given worker experiences when he changes his work location. Here, ethnicities are obviously not mobile from one country to another, ${ }^{30}$ but the reasoning is similar: the non-monetary effect of trade is identified from a change in conflicts for an ethnicity that is located in different countries and which thus encounters different conditions.

This strategy generalizes many case studies that compare how similar ethnicities have evolved on both sides of a share border (Asiwaju, 1985; Miles and Rochefort, 1991; Miles, 1994, Posner, 2004). An interesting article in that tradition is that of Miguel (2004) who analyzes two nearby rural districts in western Kenya and in western Tanzania. The main finding is that ethnicities in Tanzania, that have consistently benefited from nation-building policies, defined as investments in "social capital", have achieved better local public goods outcomes than diverse communities in Kenya. In our analysis, the first step (i.e. the term $f_{i} \times f_{t}$ ) captures a part of these country building policies, and the second step analyzes how international trade has affected these policies.

\subsection{Results}

Table (3) presents the first step regressions results from the estimation of Equation (3). The three different columns differ according to the set of fixed effects and variables that are introduced. In Column (1), we consider only ethnic group's level of income as explanatory variable. Column (2) performs the same regression as Column (1) by accounting in addition for some country level time-varying and observable characteristics. In Column (3) we consider the full set of country level-time varying features by introducing the full set of country-year fixed effects.

We first confirm here what has been observed in the previous section, such as the negative impact of ethnic income on wars. Income is indeed significant even when we control for the full set of country-year covariates.

It is also interesting to observe the significant change in the R-squared from the first to the third column. Indeed, even if the first column shows that there is a correlation between wars and income, this variable alone seems to be a poor predictor of wars. The introduction of the full set of country-year covariates in Column (3) strongly improves the goodness-of-fit measure of our regression. This means that the unobserved national context is important and must be taken into account in explaining ethnic wars.

\footnotetext{
${ }^{30}$ Although the fact that individuals are more mobile between countries with shared ethnicities reinforces our point, we don't need to use this fact to validate our argument.
} 
Table 3: First step regression

\begin{tabular}{lccc}
\hline Dep var : Ethnic war $\left(\right.$ war $\left._{\text {rit }}\right)$ & $(1)$ & $(2)$ & $(3)$ \\
\hline log Income. & $-0.0043^{* *}$ & $-0.0040^{* *}$ & $-0.0037^{*}$ \\
Population size & $(0.0019)$ & $(0.0019)$ & $(0.0022)$ \\
& & -0.0300 & \\
Polity2 & & $(0.0300)$ & \\
& & 0.0003 & \\
Polity2 square & & $(0.0002)$ & \\
& & 0.00002 & \\
GDP growth & & $(0.00003)$ & \\
& & $0.0005^{* * *}$ & \\
Temperature & & $(0.0002)$ & \\
& & 0.0016 & \\
Precipitation & & $(0.0010)$ & \\
& & $0.0001^{*}$ & \\
Constant & & $(0.0001)$ & \\
& $-0.0133^{*}$ & $-0.0115^{*}$ & $-0.0037^{*}$ \\
Observations & $(0.0070)$ & $(0.0069)$ & $(0.0022)$ \\
R-squared & 6,348 & 6,348 & 6,348 \\
Ethnic Group-Country FE & 0.011 & 0.013 & 0.260 \\
Country $\times$ Year FE $\left(f_{i} \times F_{t}\right)$ & Yes & Yes & Yes \\
No & No & Yes \\
\hline
\end{tabular}

Notes: The dependent variable is a binary variable taking 1 when an ethnic group is engaged in a new ethnic war in a given year. All explanatory variables are lagged by one year. Column 1 and 2 are estimated without taking into account country-year characteristics. Column 3 accounts for both year FE and country-year effects. Results looks exactly the same when we do not introduce year FE in column 3. The predicted country-year FE are extracted from this latter regression. Robust standard errors clustered at country level are reported in parentheses. ${ }^{* * *}(* *)(*)$ denote significance at the 1,5 and 10 percent level respectively.

As noticed in the previous sub-section, the estimated country-year fixed effects from the first step table results (from Column 3) are used as dependent variable in the second step. Table (4) presents this second step which shows the residual effect of trade beyond its effect through income. We find that our variable of international trade significantly reduces the likelihood of a country to host ethnic conflicts. 
Table 4: Second step regression

\begin{tabular}{|c|c|c|}
\hline Dep var : $f_{i} \times F_{t}$ & (1) & $(2)$ \\
\hline & \multicolumn{2}{|c|}{ International trade } \\
\hline \multirow[t]{2}{*}{ Trade $\left(\phi_{i t}\right)$} & $-0.0052^{* *}$ & $-0.0070^{* * *}$ \\
\hline & $(0.0021)$ & $(0.0024)$ \\
\hline \multirow[t]{2}{*}{ Population size } & & $0.0042^{* *}$ \\
\hline & & $(0.0019)$ \\
\hline \multirow[t]{2}{*}{ Polity 2} & & $-0.0010^{*}$ \\
\hline & & $(0.0005)$ \\
\hline \multirow[t]{2}{*}{ Polity2 square } & & 0.0001 \\
\hline & & $(0.0001)$ \\
\hline \multirow[t]{2}{*}{ GDP growth } & & 0.0005 \\
\hline & & $(0.0004)$ \\
\hline \multirow[t]{2}{*}{ Constant } & $0.0242^{* *}$ & -0.0406 \\
\hline & $(0.0107)$ & $(0.0249)$ \\
\hline Estimator & OLS & OLS \\
\hline Observations & 569 & 569 \\
\hline R-squared & 0.070 & 0.080 \\
\hline Year FE & Yes & Yes \\
\hline
\end{tabular}

Notes: This Table presents the results from the second step (3). All explanatory variables are lagged by one year. Trade designs respectively International trade, Internal trade and Regional trade. Predicted values of time-varying country effects are used as dependent variables and comes from Column 3 of Table (3). Robust standard errors robust to clustering at country level reported in parenthesis. ${ }^{* * *}(* *)(*)$ denote significance at the 1,5 and 10 percent level respectively.

This two-steps approach is complementary to the first part of this paper regarding the peaceful effect of trade. It shows that the effect of international trade has the potential to shape national characteristics in a ways that foster peace between ethnic groups in Africa.

\section{Conclusion}

The beneficial impact of international trade on peace has been at the heart and soul of many trade agreements in Europe, Latin America and Africa. Its effect on conflicts inside countries is a more recent topic of research. Our aim was to analyze whether international trade has still an impact on conflicts once we control for the main determinants emphasized by the literature such as the different levels of income between ethnicities, political domination by one group, dramatic climate change and other constant unobservable factors. To do so, we build indicators of international trade at the ethnic group level and we propose different empirical strategies, among which a two-stage analysis enabling the separation of the income effect from other effects. In all of our estimations, international trade favors peace. This result may be seen as contradictory to the existing literature that often finds that trade is a source of conflict. This is not the case. In analyzing global exogenous price shocks, many papers focus on the short-run effects of international trade. Here, we analyze effects that are more continuous and that progressively affect different ethnic groups inside countries. 
These effects are certainly more difficult to capture because of various endogeneity biases, but should not be overlooked.

\section{References}

[1] Abowd, J. M., Kramarz, F., \& Margolis D. N. (1999). 'High wage workers and high wage firms', Econometrica, 67, pp. 251-334.

[2] Angrist, J. D., \& Kugler, D. (2008). 'Rural windfall or a new resource curse? coca, income and civil conflict in Colombia', The Review of Economics and Statistics, 90, pp. $191-215$.

[3] Asiwaju, A. I. (1985). Partitioned Africa: Ethnic relations across Africa's international boundaries, 1884-1984, London: C. Hurst.

[4] Bazzi, S., \& Blattman, C. (2014). 'Economic shocks and conflict: evidence from commodity prices, American Economic Journal of Macroeconomics', 6, pp. 1-38.

[5] Berman, N., \& Couttenier, M. (2015). 'External Shocks, Internal Shots: The Geography of Civil Conflicts', The Review of Economics and Statistics, 97, pp. 758-776

[6] Berman, N., Couttenier, M., Soubeyran, R. (2021). 'Fertile Ground for Conflict'. Journal of European Economic Association, 19, pp. 82-127.

[7] Bisin, A., \& Verdier, T. (2014). 'Trade and cultural diversity'. Handbook of the Economics of Art and Culture, 2, pp. 439-484.

[8] Bruederle, A., \& Hodler, R. (2017). 'Nighttime Lights as a Proxy for Human Development at the Local Level'. CESifo Working Paper No. 6555. Retrieved from https://www.cesifo.org/en/publikationen/2017/working-paper/nighttimelights-proxy-human-development-local-level

[9] Cali, M. (2015). 'Trading Away from Conflict Using Trade to Increase Resilience in Fragile States (English)'. World Bank Group Report. Retrieved from https://documents.worldbank.org/en/publication/documentsreports/documentdetail/475581468330024333/trading-away-from-conflict-using-tradeto-increase-resilience-in-fragile-states

[10] Candau, F., \& Dienesch, E. (2017). 'Pollution Haven and Corruption Paradise', Journal of Environmental Economics and Management, 85, pp. 171-192.

[11] Caplan, B., \& Cowen, T. (2004). 'Do We Underestimate the Benefits of Cultural Competition?', American Economic Review, 94, 402407.

[12] Combes, P.-P., Duranton, G., \& Gobillon, L. (2008). 'Spatial wage disparities: Sorting matters!', Journal of Urban Economics 63, pp. 723-742. 
[13] Cowen, T. (2002). Creative destruction: How globalization is shaping the worlds cultures. Princeton. NJ: Princeton University Press.

[14] Chandler, T. (1987). Four Thousand Years of Urban Growth: An Historical Census. Edwin Mellon Press, Lewiston, NY.

[15] Cunningham, S. (2021). Causal inference: The mixtape. Yale University Press.

[16] Dube, O., and J. Vargas. 2013. 'Commodity Price Shocks and Civil Conflict: Evidence from Colombia', Review of Economic Studies 80 (4): 1384-1421.

[17] Fleurbaey, M., (2015). Forced trades in a free market, in C. Binder, G. Codognato, M. Teschl, Y. Xu (eds.), Individual and Collective Choice and Social Welfare. Essays in Honor of Nick Baigent, Springer.

[18] Gibson, J., Olivia, S., Boe-Gibson, G., \& Li, C. (2021). 'Which night lights data should we use in economics, and where?', Journal of Development Economics, 149, 102602.

[19] Gleditsch, K. (2007). 'Transnational Dimensions of Civil War', Journal of Peace Research, 44, pp. 293-309.

[20] Gurr, T. (1970). Why Men Rebel. Paradigm Publishers.

[21] Henderson, J. V., Storeyguard A., \& Weil, D. N. (2012). 'Measuring Economic Growth from Outer Space', American Economic Review, 102, pp. 994-1028.

[22] Horowitz, D. (1985). Ethnic Groups in Conflict. University of California Press.

[23] Hsiang, S. M., Burke, M., \& Miguel, E. (2013). 'Quantifying the influence of climate on human conflict', Science, 341, 1235367.

[24] Humphreys, M., \& Weinstein, J. M. (2008). 'Who fights? the determinants of participation in civil war', American Journal of Political Science, 52, 436-455.

[25] McGuirk, E., \& Burke, M. (2020). 'The economic origins of conflict in Africa', Journal of Political Economy, 128, pp. 3940-3997.

[26] Maystre, N., Olivier, J., Thoenig, M., \& Verdier, T. (2014). 'Product-Based Cultural Change: Is the Village Global?', Journal of International Economics, 92, pp. 212-230

[27] Maystadt, J-F., De Luca, G., Sekeris, P. G., Ulimwengu, J., \& R. Folledo. (2014). 'Mineral Resources and Conflicts in DRC: A Case of Ecological Fallacy?' Oxford Economic Papers, 66, pp. 721-49.

[28] Martin P., Mayer T., \& Thoenig, M.(2008a). 'Make Trade Not War?' Review of Economic Studies, 75, pp. 865-900.

[29] Martin P., Mayer T., \& Thoenig, M. (2008b). 'Civil War and International Trade', Journal of European Economic Association, 6, pp. 541-550. 
[30] McGuirk, E. F., \& Nunn, N. (2020). Nomadic Pastoralism, Climate Change, and Conflict in Africa. National Bureau of Economic Research Working papers No. w28243. Retrieve from https://www.nber.org/papers/w28243

[31] Michalopoulos, S., \& Papaioannou, E. (2013). 'Pre-Colonial Ethnic Institutions and Contemporary African Development', Econometrica, 81, pp. 113-152

[32] Michalopoulos, S., \&d Papaioannou, E. (2016). 'Pre-colonial Ethnic Institutions and Contemporary African Development', Econometrica, 81, pp. 113-152

[33] Michalopoulos, S., \& Papaioannou, E. (2016). 'The Long Run Effects of the Scramble for Africa', American Economic Review, 106, pp. 1802-1848.

[34] Michalopoulos, S. \& Papaioannou, E. (2018). 'Spatial Patterns of Development: A Meso Approach', Annual Review of Economics, 10, pp. 383-410.

[35] Miguel, E. (2004): 'Tribe or Nation? Nation-Building and Public Goods in Kenya versus Tanzania', World Politics, 56, pp. 327-362.

[36] Miguel, E., Satyanath, S., \& Sergenti, E. (2004). 'Economic shocks and civil conflict: An instrumental variables approach', Journal of Political Economy, 112, pp. 725-753

[37] William, M. F. S., \& Rochefort, D. A. (1991). Nationalism versus ethnic identity in sub-Saharan Africa. American Political Science Review, 85, 393-403.

[38] William M. F. S. (1994). Hausaland divided: Colonialism and independence in Nigeria and Niger. Ithaca, NY: Cornell University Press.

[39] Montesquieu, (1758), De l'esprit des lois.

[40] Moulton, B. R. (1990). 'An Illustration of a Pitfall in Estimating the Effects of Aggregate Variables on Micro Units', The Review of Economics and Statistics, 72, pp. 334-338

[41] Monfreda, C., Ramankutty, N. \& Foley, J. A. (2008). Farming the planet: 2. Geographic distribution of crop areas, yields, physiological types, and net primary production in the year 2000, Global Biogeochem. Cycles, 22, GB1022, doi:10.1029/2007GB002947.

[42] Murdock, G. P. (1959). Africa: Its Peoples and their Culture History. McGraw-Hill.

[43] Nordhaus, W. \& Chen, X. (2015). 'A sharper image? Estimates of the precision of night time lights as a proxy for economic statistics'. Journal of Economic Geography 15, pp. 217-246.

[44] Posner, D. N. (2004). 'The political salience of cultural difference: Why Chewas and Tumbukas are allies in Zambia and adversaries in Malawi', American Political Science Review, 98, pp. 529-545.

[45] Rauch, J. E. \& Trindade, R. (2009). 'Neckties in the tropics: a model of international trade and cultural diversity', Canadian Econ Journal, 42, pp. 809-1205. 
[46] Rohner, D., Thoenig, M., \& Zilibotti, F. (2013). 'War signals: A theory of trade, trust, and conflict', Review of Economic Studies, 80, pp. 1114-1147.

[47] Ross, M. L. (2015). 'What have we learned about the resource curse?' Annual Review of Political Science, 18, pp. 239-259.

[48] Sarsons, H. (2015). 'Rainfall and conflict: A cautionary tale', Journal of Development Economics, 115, pp. 62-72.

[49] Weidmann, N. B., \& S. Schutte (2017). 'Using Night Light Emissions for the Prediction of Local Wealth', Journal of Peace Research, 54, pp. 125-140.

[50] Wimmer A., Cederman L. E., \& Min, B.(2009). 'Ethnic Politics and Armed Conflict: A Configurational Analysis of a New Global Data Set', American Sociological Review, 74, pp. 316-337. 